\title{
Analisis Stres dan Penyesuaian Diri pada Mahasiswa
}

\author{
Yudi Suharsono1, Zainul Anwar \\ Fakultas Psikologi Universitas Muhammadiyah Malang \\ Email: 1yudisuharsono@umm.ac.id, 2zainulanwar@umm.ac.id
}

\begin{abstract}
Mahasiswa membuat seseorang memiliki peran baru dalam dunia Pendidikan di Perguruan Tinggi. Ditemukan banyak perubahan dalam kehidupan barunya tersebut sehingga membutuhkan kemampuan penyesuaian diri yang baik. Kemampuan penyesuaian diri yang kurang baik dapat menyebabkan seorang mahasiswa mengalami stres. Hasil penelitian ini dapat digunakan sebagai dasar acuan pembinaan kemahasiswaan yang lebih sesuai dengan karakteristik masing masing individu yang selanjutnya dikelompokkan berdasar karakteristik yang berdekatan. Menjadi dasar pemberian perlakuan yang tepat agar hasil pembelajaran menjadi optimal. Pengumpulan data menggunakan skala stres dan penyesuaian diri. Tujuan penelitian untuk mengetahui gambaran stres dan penyesuaian diri mahasiswa. Subjek penelitian sebanyak 2320 mahasiswa. Hasil penelitian menggambarkan bahwa mahasiswa yang dalam kategori stres sedang sebanyak 55\%, sebanyak $45 \%$ dalam kategori stres rendah, dan tidak ditemukan tingkat stres yang dalam kategori tinggi. Adapun Penyesuaian diri mahasiswa dalam kategori sedang sebanyak $88 \%$, sebanyak $11 \%$ berada pada level penyesuaian diri rendah, dan 1\% yang berada pada level tinggi.
\end{abstract}

KEYWORDS stres, penyesuaian diri, mahasiswa

CITATION Suharsono, Y., Anwar, Z. (2020). Analisis stres dan penyesuaian diri pada mahasiswa. Cognicia, 8, (1). 1-12.

Merupakan tantangan tersendiri ketika seseorang menjadi mahasiswa, panggilan bagi individu yang belajar di perguruan tinggi. Setiap orang memiliki kondisi yang berbeda untuk menghadapi tantangan dan masalah yang dihadapinya. Berbagai masalah sering timbul dalam proses adaptasi mahasiswa, baik itu dengan lingkungan perkuliahan maupun tempat tinggal barunya. Mulai dari penyesuaian dengan sistem perkuliahan, teman-teman, lingkungan, dan budaya baru. Terlebih bagi mahasiswa yang berasal dari luar kota dan jauh dari keluarga. Setiap mahasiswa memiliki tingkat penyesuaian diri 
yang berbeda-beda. Ada yang biasa saja saat menghadapi dunia barunya. Beberapa lainnya merasa sedikit kaget karena merasa bahwa ini adalah saatnya memasuki dunia baru, yakni dunia mahasiswa dan meninggalkan masa sekolahnya. Selamat datang, dunia baru, katanya. Namun, ada pula yang sedikit atau bahkan sangat kaget dengan dunia barunya ini.

Perbedaan sikap tersebut dilatarbelakangi oleh berbagai faktor. Pertama, setiap individu memiliki karakter yang berbeda dalam menyikapi suatu hal dan beradaptasi dengan lingkungan. Ada tipikal orang yang mudah menyesuaikan diri dengan lingkungan dan sistem baru, sehingga ia tidak mengalami stres dan menikmati semuanya. Tipikal seperti ini mudah menyesuaikan diri dengan sistem perkuliahan yang berbeda dengan sekolahnya dulu. Tipe yang lain adalah tipikal orang yang susah dan membutuhkan beberapa waktu untuk beradaptasi dengan lingkungan baru. Ia mungkin akan mendapat sedikit masalah mengenai sistem yang baru dikenalnya. Ini bukan merupakan suatu masalah besar jika ia dapat mengatasi stres tersebut.

Faktor yang kedua, yaitu perbedaan latar belakang masing-masing individu. Latar belakang ini bisa meliputi latar belakang pendidikan, sosial, budaya, dan ekonomi. Dunia perkuliahan memang memiliki sistem yang berbeda sekolah. Untuk mahasiswa yang berasal dari sekolah yang sudah maju, maka akan mudah menyesuaikan diri dengan sistem perkuliahan. Bahkan, saat ini sudah ada beberapa sekolah yang menerapkan sistem indeks prestasi (IP) untuk mengukur kemampuan siswa, sama seperti sistem perkuliahan, terutama dalam masalah informasi dan teknologi.

Faktor ketiga adalah perbedaan motivasi kuliah. Mahasiswa yang memang berkuliah karena berasal dari keinginan sendiri akan benar-benar serius dan tidak mainmain dalam menjalani kehidupan kuliahnya. Apapun masalahnya, ia akan berusaha menghadapi kendala demi tercapainya mimpi. Namun, tak sedikit juga mahasiswa yang mengambil suatu jurusan tertentu bukan karena keinginan pribadinya, semisal karena tuntutan orang tua atau diterima di jurusan yang bukan pilihan utamanya. Ini akan 
menjadi masalah besar jika ia belum bisa berdamai dengan pilihannya. Ia akan menjalani masa-masa kuliah dengan berat hati, merasa tertekan, dan malas.

Dengan demikian, masalah yang dihadapi mahasiswa baru berkaitan dengan lingkungan perkuliahan berbeda pada masing-masing individu, sehingga cara penyelesaiannya pun berbeda. Bagaimanapun karakter dan latar belakang seorang mahasiswa baru, yang terpenting adalah meluruskan niat dalam menuntut ilmu, memantapkan tujuan, dan tidak pernah berhenti belajar. Jika tiga hal tersebut sudah dimiliki, maka problematika apapun dapat diatasi dengan baik.

Ketika seseorang tidak mampu mengatasi masalah masalah di atas, maka dia akan mengalami keadaan psikologis yang tidak menyenanangkan dan berakibat stres. Stres adalah suatu bentuk ketegangan fisik, psikis, emosi, dan mental, yang dialami oleh seseorang sehingga dapat memengaruhi kegiatan orang tersebut. Dari sisi psikologis, pengertian stres disebut juga sebagai suatu gangguan mental yang terjadi pada seseorang akibat adanya tekanan yang berasal dari luar maupun dalam dirinya sendiri. Stres yang dialami seseorang dapat mengakibatkan menurunnya produktivitas seseorang dalam berkegiatan, bahkan dapat menimbulkan rasa sakit pada tubuh.

Sebagai individu yang memiliki kemampuan menyelesaikan masalah, maka seseorang tidak bisa terlepas dari proses penyesuaian diri, seperti penyesuaian diri terhadap lingkungan sekitar, penyesuaian diri terhadap orang-orang, bahkan penyesuaian diri terhadap diri sendiri serta hambatan-hambatan yang ada dalam hidup. Penyesuaian diri (self adjustment) merupakan proses untuk memperoleh atau memenuhi kebutuhan (needs satisfaction), mengatasi konflik, frustasi, serta masalah-masalah tertentu dengan cara-cara tertentu.

Proses penyesuaian ini secara tidak langsung memengaruhi kesehatan mental seseorang. Kesehatan mental seseorang sangat penting bagi kelangsungan hidup setiap individu. Kesehatan mental yang baik akan melahirkan jiwa yang sehat dan berlaku sebaliknya. Kemampuan penyesuaian diri yang kurang baik juga dapat menimbulkan masalah-masalah kesehatan mental selama rentang kehidupan. Kehidupan tidak 
selamanya berjalan lancar dan sesuai keinginan. Adanya hambatan dalam pemenuhan kebutuhan dan pemuasan diri dapat mengganggu kapasitas penyesuaian diri seseorang.

Penelitian ini bertujuan untuk mengetahui gambaran stres dan penyesuaian diri pada mahasiswa Universitas Muhammadiyah Malang tahun akademik 2018/2019. Selanjutnya dapat digunakan sebagai salah satu acuan pembinaan dalam bidang kemahasiswaan yang lebih tepat karena sesuai dengan keadaan nyata mahasiswa.

\section{Stres}

Stres adalah suatu kondisi yang dinamis saat seorang individu dihadapkan pada peluang, tuntutan, atau sumber daya yang terkait dengan apa yang dihasratkan dan dianggap penting oleh individu tersebut, namun dihadapkan dengan kondisi yang hasilnya tidak pasti. Stres adalah beban yang melebihi kemampuan maksimum rohani, sehingga perbuatan kurang terkontrol secara sehat. Stres merupakan suatu persepsi dari ancaman atau suatu bayangan akan adanya ketidaksenangan yang menggerakkan, menyiagakan, atau membuat aktif organisme. Sedangkan menurut Handoko (1997), stres adalah suatu kondisi ketegangan yang memengaruhi emosi, proses berpikir, dan kondisi seseorang. Stres yang terlalu besar dapat mengancam kemampuan seseorang untuk menghadapi lingkungannya. Woolfolk dan Richardson (1979) menyatakan bahwa adanya sistem kognitif, apresiasi stres dapat menyebabkan segala peristiwa yang terjadi di sekitar kita dihayati sebagai suatu stres berdasarkan arti atau interprestasi yang kita berikan terhadap peristiwa tersebut, dan bukan karena peristiwa itu sendiri. Karenanya, dikatakan bahwa stres adalah semua perubahan yang memerlukan penyesuaian serta penyelesaian. Di bawah ini adalah beberapa definisi lain terkait stress.

1) Lazarus dan Folkman (1984) mendefinisikan stres sebagai segala sesuatu yang dipandang oleh seseorang sebagai sesuatu yang menantang, mengancam, atau menyakitkan (Lazarus \& Folkman, dalam Wortman, 1999). 
2) Holmes dan Rahe mendefnisikan stres sebagai suatu keadaan di mana individu harus berubah dan menyesuaikan diri terhadap suatu peristiwa yang terjadi (Holmes \& Rahe dalam Aronson, 2004).

3) Papalia (2004) mendefinisikan stres sebagai respon terhadap tuntutan fisik ataupun psikologis.

\section{Penyesuaian diri}

Penyesuaian adalah suatu proses yang tidak bisa dipisahkan oleh seluruh makhluk hidup. Tak hanya manusia, hewan dan tumbuhan juga mengalami penyesuaian, baik dengan dirinya sendiri, sesame, bahkan lingkungan sekitar. Individu yang tidak mampu melakukan penyesuaian maka akan mudah hilang, terusir, dan tidak bisa melanjutkan keberadaannya. Penyesuaian diri atau biasa dikenal dengan self adjusment adalah istilah yang memiliki banyak makna. Tidak ada yang namanya penyesuaian diri baik atau buruk.

Penyesuaian diri adalah bentuk reaksi individu atau organisme khusus terhadap tuntutan-tuntutan dari situasi luar. Beberapa definisi tentang penyesuaian diri adalah sebagai berikut.

1) Tyson (1951), kemampuan beradaptasi, berafeksi, kehidupan seimbang, kemampuan mengambil keuntungan dari pengalaman, toleransi terhadap frustasi, humor, sikap yang tidak ekstrem, objektivitas, dan lain-lain

2) Calhoun dan Acocella, interaksi yang dilakukan secara kontinu atau berkelanjutan dengan diri sendiri maupun orang lain,

3) Kartini Kartono (2002), usaha yang dilakukan oleh manusia dalam mencapai harmoni atau kesatuan untuk diriya sendiri dan lingkungan sekitar agar bisa memusnahkan rasa permusuhan, rasa dengki, iri hati, sebuah prasangka, gangguan depresi, ekspresi kemarahan, dan emosi negatif yang dianggap sebagai respon pribadi yang tidak sesuai dan kurang efisien.

4) Schneiders, bentuk proses yang melingkupi reaksi mental dan tingkah laku, di mana individu sedang berupaya untuk mengambil keberhasilan dalam mengatasi 
kebutuhan-kebutuhan di dalam dirinya, ketegangan-ketegangan, konflik-konflik, dan frustrasi yang dialaminya, sehingga tingkat keselarasan antara tuntutan dalam diri dengan apa yang diinginkan oleh lingkungan di mana dia tinggal dapat terwujud dengan baik. (dalam Desmita, 2009).

\section{METODE PENELITIAN}

Penelitian ini menggunakan pendekatan kuantitatif deskriptif. Pengumpulan data menggunakan instrumen Perceived Stres Scale (PSS) dan 2) The College Adjustment Test (CAT) dengan subjek mahasiswa Universitas Muhammadiyah Malang tahun akademik 2018/2019 sebanyak 2.320 mahasiswa dari berbagai fakultas.

Teknik analisis data menggunakan analisis deskriptif kuantitaif dengan mempresentasekan sesuai dengan kategori dari variabel penelitian. Sebelum penelitian, terlebih dahulu dilakukan pengujian instrumen penelitian untuk mengetahui validitas dan reliabilitas dari ketiga skala yang digunakan.

\section{HASIL DAN PEMBAHASAN}

Subjek penelitian berusia antara 18 - 24 tahun sebanyak 2.320 mahasiswa yang terdiri dari beberapa fakultas. Data secara detail dapat dilihat pada tabel berikut.

Tabel 1. Subjek Penelitian

\begin{tabular}{lll}
\hline No & Subjek & Jumlah \\
\hline 1 & FPP & 641 \\
2 & FISIP & 574 \\
3 & FK & 78 \\
4 & FT & 269 \\
5 & F.PSI & 288 \\
6 & FIKES & 470 \\
\hline
\end{tabular}




Total 2320

Tabel 2. Deskripsi stres

\begin{tabular}{|c|c|c|c|c|c|c|c|c|}
\hline \multirow{3}{*}{ No } & \multirow{3}{*}{ Subjek } & \multicolumn{5}{|c|}{ Kategori } & \multirow{2}{*}{\multicolumn{2}{|c|}{ Total }} \\
\hline & & Tinggi & \multicolumn{2}{|c|}{ Sedang } & \multicolumn{2}{|c|}{ Rendah } & & \\
\hline & & $\%$ & $\mathrm{f}$ & $\%$ & $\mathrm{f}$ & $\%$ & $\mathrm{f}$ & $\%$ \\
\hline 1 & FPP & 0 & 218 & 34 & 423 & 66 & 641 & 100 \\
\hline 2 & FISIP & 0 & 372 & 65 & 202 & 35 & 574 & 100 \\
\hline 3 & FK & 0 & 56 & 72 & 22 & 28 & 78 & 100 \\
\hline 4 & FT & 0 & 60 & 22 & 209 & 78 & 269 & 100 \\
\hline 5 & F.PSI & 0 & 222 & 77 & 66 & 23 & 288 & 100 \\
\hline \multirow[t]{2}{*}{6} & FIKES & 0 & 347 & 74 & 123 & 26 & 470 & 100 \\
\hline & & 0 & 1275 & 55 & 1045 & 45 & 2320 & 100 \\
\hline
\end{tabular}

Tabel 3. Deskripsi Penyesuaian Diri

\begin{tabular}{|c|c|c|c|c|c|c|c|c|c|}
\hline \multirow{3}{*}{ No } & \multirow{3}{*}{ Subjek } & \multicolumn{6}{|c|}{ Kategori } & \multirow{2}{*}{\multicolumn{2}{|c|}{ Total }} \\
\hline & & \multicolumn{2}{|c|}{ Tinggi } & \multicolumn{2}{|c|}{ Sedang } & \multicolumn{2}{|c|}{ Rendah } & & \\
\hline & & $\mathrm{f}$ & $\%$ & $\mathrm{f}$ & $\%$ & $\mathrm{f}$ & $\%$ & $\mathrm{f}$ & $\%$ \\
\hline 1 & FPP & 2 & 0 & 588 & 92 & 51 & 8 & 641 & 100 \\
\hline 2 & FISIP & 5 & 1 & 493 & 86 & 76 & 13 & 574 & 100 \\
\hline 3 & FK & 1 & 1 & 72 & 92 & 5 & 6 & 78 & 100 \\
\hline 4 & FT & 3 & 1 & 233 & 87 & 33 & 12 & 269 & 100 \\
\hline 5 & F.PSI & 3 & 1 & 239 & 83 & 46 & 16 & 288 & 100 \\
\hline 6 & FIKES & 1 & 0 & 424 & 90 & 45 & 10 & 470 & 100 \\
\hline & & 15 & 1 & 2049 & 88 & 256 & 11 & 2320 & 100 \\
\hline
\end{tabular}


Mahasiswa merupakan salah satu bagian dari civitas akademika pada perguruan tinggi yang merupakan calon pemimpin bangsa di masa yang akan datang. Untuk itu, mahasiswa perlu memiliki cara pandang yang baik dan kepribadian yang sehat dan kuat agar tidak mudah stres dan putus asa.

Mahasiswa harus menguasai permasalahan sesulit apapun dan mempunyai cara berpikir positif terhadap dirinya dan orang lain. Ia harus mampu mengatasi hambatan maupun tantangan yang dihadapi dan tentunya pantang menyerah pada keadaan yang ada. Tuntutan kehidupan, baik dari dalam maupun dari luar kampus, menuntut mahasiswa untuk dapat menghadapi masalah yang muncul dengan lebih dewasa, bertanggungjawab, tangguh dan kuat. Belum lagi desakan untuk menyelesaikan studi lulus tepat waktu, persiapan menyusun skripsi, persiapan untuk mendapatkan kesempatan pekerjaan atau karir setelah lulus, serta tuntutan orang tua dan universitas membuat mahasiswa menjadi tertekan bahkan muncul berbagai pikiran-pikiran negatif pada dirinya.

Berdasarkan hasil penelitian, tingkat stres secara keseluruhan mahasiswa sebanyak 55\% dalam kategori sedang dan sebanyak 45\% dalam kategori stres rendah. Tidak ditemukan tingkat stres dalam kategori tinggi. Data tersebut menggambarkan bahwa mahasiswa secara keseluruhan memiliki pengelolaan stres yang baik, namun terdapat $45 \%$ yang rendah tingkat stresnya, hal ini berdampak pada motivasi mahasiswa, semakin tidak memiliki tingkat stres atau tekanan berarti semakin “tidak melakukan apaapa" sehingga berdampak pada prestasi mahasiswa.

Cukup banyak kasus maupun percobaan bunuh diri dan tindakan brutal yang terjadi pada mahasiswa. Hal tersebut menggambarkan adanya gejala-gejala stres pada mahasiswa mulai dari tingkat ringan sampai berat yang kemudian berakhir dengan sangat tragis. Fenomena ini tentunya sangat penting untuk dikaji (Kholidah \& Alsa, 2012). Hasil penelitian menyatakan bahwa mahasiswa yang sedang menyusun skripsi dan melakukan penundaan penyelesaian skripsi mengalami peningkatan tingkat stres yang cukup tinggi (Gunawati, Hartati, \& Listiara, 2010). 
Penelitian yang dilakukan di Universitas Bostwana oleh Joseph (2009) menguraikan bahwa sumber stres bagi mahasiswa meliputi managemen waktu, tuntutan akademik, dan lingkungan akademik. Sumber stres tersebut dijabarkan berupa tugastugas akademik, penurunan motivasi, jadwal perkuliahan yang padat dan tidak jelas, serta kecemasan tidak mendapatkan pekerjaaan setelah lulus kuliah. Selain itu diperoleh pula bahwa tingkat stres pada mahasiswa perempuan lebih tinggi dibanding mahasiswa lakilaki.

Stres merupakan salah satu reaksi atau respon psikologis manusia saat dihadapkan pada hal-hal yang dirasa telah melampaui batas atau dianggap sulit untuk dihadapi. Setiap manusia mempunyai pengalaman terhadap stres bahkan sebelum manusia lahir. Stres normal dialami oleh setiap individu dan menjadi bagian yang tidak terpisahkan dalam kehidupan. Stres membuat seseorang berpikir dan berusaha keras dalam menyelesaikan suatu permasalahan atau tantangan dalam hidup sebagai bentuk respon adaptasi untuk tetap bertahan (Potter \& Perry, 2005). Tanggung jawab dan tuntutan kehidupan akademik pada mahasiswa dapat menjadi bagian stres yang biasa dialami oleh mahasiswa (Potter \& Perry, 2005; Smeltzer et al., 2008)

Studi literatur stres pada remaja cenderung tinggi. Jumlah mahasiswa yang mengalami stres akademik meningkat setiap semester. Stres yang paling umum dialami oleh mahasiswa merupakan stres akademik. Stres akademik diartikan sebagai suatu keadaaan individu mengalami tekanan hasil persepsi dan penilaian tentang stresor akademik, yang berhubungan dengan ilmu pengetahuan dan pendidikan di perguruan tinggi (Govaerts \& Grégoire, 2004; Wong, Hockenberry, \& Wilson, 2007).

Hasil penelitian menjelaskan, sumber stres pada mahasiswa adalah adanya kegagalan dalam menyelesaikan tuntutan akademik, penundaan penyelesaian tugas, prestasi akademik yang rendah, dan masalah kesehatan (Purwati, 2012). Adapun dampak positif dari stress yakni berupa peningkatan kreativitas dan memicu pengembangan diri selama stres yang dialami masih dalam batas kapasitas individu. Stres tetap dibutuhkan untuk pengembangan diri mahasiswa. Respon stres dari setiap mahasiswa berbeda. 
Respon tersebut tergantung pada kondisi kesehatan, kepribadian, pengalaman sebelumnya terhadap stres, mekanisme koping, jenis kelamin dan usia, besarnya stresor, dan kemampuan pengelolaan emosi dari masing-masing individu (Potter \& Perry, 2005; Smeltzer et al., 2008).

Stres akan timbul jika tuntutan-tuntutan pada individu yang dirasakan menantang, menekan, membebani atau melebihi daya penyesuaian diri pada individu. Tiap orang mempunyai cara-cara penyesuaian diri yang berbeda, yang tergantung dari kemampuan-kemampuan yang dimiliki, pengaruh-pengaruh lingkungan, pendidikan dan bagaimana ia mengembangkan dirinya. Dalam menghadapi stres, seseorang dapat mengadakan penyesuaian diri secara efektif, yaitu mengarahkan tindakannya pada sasaran tertentu untuk mengatasi sebab-sebab stres.

Penyesuaian diri secara keseluruhan mahasiswa berada dalam kategori sedang sebanyak $88 \%$, sebanyak $11 \%$ berada pada level penyesuaian diri rendah, dan $1 \%$ yang berada pada level tinggi. Penyesuaian diri yang rendah berdampak pada aktivitas sosial mahasiswa.

Schneiders (1964) menguraikan bahwa individu yang memiliki penyesuaian diri yang baik (well adjustment person) adalah mereka dengan segala keterbatasannya, kemampuannya serta kepribadiannya telah belajar untuk bereaksi terhadap diri sendiri dan lingkungannya dengan cara efisien, matang, bermanfaat, dan memuaskan. Efisien artinya bahwa apa yang dilakukan individu tersebut dapat memberikan hasil yang sesuai dengan yang diinginkan tanpa banyak mengeluarkan energi, tidak membuang waktu banyak, dan sedikit melakukan kesalahan. Matang artinya bahwa individu tersebut dapat memulai dengan melihat dan menilai situasi dengan kritis sebelum bereaksi. Bermanfaat artinya bahwa apa yang dilakukan individu tersebut bertujuan untuk kemanusiaan, berguna dalam lingkungan sosial, dan yang berhubungan dengan Tuhan. Selanjutnya, memuaskan artinya bahwa apa yang dilakukan individu tersebut dapat menimbulkan perasaan puas pada dirinya dan membawa dampak yang baik pada dirinya dalam bereaksi selanjutnya. Mereka juga dapat menyelesaikan konflik-konflik mental, frustasi 
dan kesulitan-kesulitan dalam diri maupun kesulitan yang berhubungan dengan lingkungan sosialnya serta tidak menunjukkan perilaku yang memperlihatkan gejala menyimpang.

\section{SIMPULAN DAN IMPLIKASI}

Berdasarkan hasil penelitian dapat disimpulkan bahwa mahasiswa yang memiliki kategori stres sedang adalah sebanyak 55\%. Sedangkan 45\% lainnya berada dalam kategori stres rendah, dan tidak ditemukan tingkat stres yang dalam kategori tinggi. Adapun penyesuaian diri mahasiswa dalam kategori sedang sebanyak $88 \%$, sebanyak $11 \%$ berada pada level penyesuaian diri rendah, dan 1\% yang berada pada level tinggi. Implikasi dari penelitian mahasiswa perlu untuk belajar manajemen diri dan memotivasi diri, khususnya bagi mahasiswa yang memiliki tingkat stres rendah dan bagi yang memiliki penyesuaian diri rendah dan unit terkait seperti unit Bimbingan dan Konseling perlu melakukan pelatihan menajemen diri agar mahasiswa memiliki ketrampilan dalam mengelola stres dan penyesuaian dirinya.

\section{REFERENSI}

Antony, M. M., Bieling, P. J., Cox, B. J., Enns, M. W., \& Swinson, R. P. (1998). Psychometric properties of the 42-item and 21-item versions of the Depression Anxiety Stres Scales in clinical groups and a community sample. Psychological Assessment, 10(2), 176.

Aronson, J. (2004). The threat of stereotype. Educational Leadership, 62, 14-20.

Cook, C., Burgess-Limerick, R., \& Papalia, S. (2004). The effect of upper extremity support on upper extremity posture and muscle activity during keyboard use. Applied ergonomics, 35(3), 285-292.

Crawford, J. R., \& Henry, J. D. (2003). The Depression Anxiety Stres Scales (DASS): Normative data and latent structure in a large non-clinical sample. British Journal of Clinical Psychology, 42(2), 111-131.

Desmita, D. (2009). Psikologi Perkembangan Peserta Didik. Remaja Rosdakarya.

Govaerts, S., \& Grégoire, J. (2004). Stresful academic situations: Study on appraisal variables in adolescence. Revue Europeenne de Psychologie Appliquee, 54(4), 261-271. https://doi.org/10.1016/j.erap.2004.05.001

Gunawati, R., Hartati, S., \& Listiara, A. (2010). Hubungan antara efektivitas komunikasi mahasiswa-dosen pembimbing utama skripsi dengan stres dalam menyusun skripsi 
pada mahasiswa Program Studi Psikologi Fakultas Kedokteran Universitas Diponegoro. Jurnal Psikologi, 3(2), 93-115.

Handoko, T. H. (2008). Manajemen Personalia dan Sumber Daya. Manusia (edisi 2). Yogyakarta: BPFE

Lazarus, R. S., \& Folkman, S. (1984). Coping and adaptation. The handbook of behavioral medicine, 282325.

Joseph, E. (2009). An assessment of academic stres among undergraduate students: The case of University of Botswana. Educational Research and Reviews, 4(2), 63.

Kholidah, E., \& Alsa, a. (2012). Berpikir Positif untuk Menurunkan Stres Psikologis. Jurnal Psikologi, 39(1), 67-75. https://doi.org/10.22146/JPSI.6967

Notosoedirdjo, M. (2000). Latipun. Kesehatan Mental Konsep dan Penerapannya. Malang.

Potter, P. A., \& Perry, A. G. (2005). Buku ajar fundamental keperawatan: konsep, proses, dan praktik. Jakarta: Egc (Vol. 1).

Psychology Foundation of Australia. (2014). Depression anxiety stres scale.

Purwati, S. (2012). Tingkat Stres Akademik pada Mahasiswa Reguler Angkatan 2010 Fakultas Ilmu Keperawatan Universitas Indonesia.

Rathus, S. A., \& Nevid, J. S. (2002). Psychology and the challenges of life: adjustment in the new millennium. Wiley.

Santrock, J. W. (1996). Adolescence: an introduction. Brown \& Benchmark Publishers.

Schneiders. (1964). Personal Adjustment and Mental Health. New York: Holt, Reinhart \& Winston Inc.

Smeltzer, S. C., Bare, B. G., Hinkle, J. L., Cheever, K. H., Townsend, M. C., \& Gould, B. (2008). Brunner and Suddarth's textbook of medicalsurgical nursing 10th edition. Philadelphia: Lipincott Williams \& Wilkins.

Suryani, E. W., Hernawati, T., \& Sriati, A. (2016). Psikoedukasi menurunkan tingkat depresi, stres dan kecemasan pada pasien tuberkulosis paru. Jurnal Ners, 11(1), 128133.

Tyson, R. (1951). Current mental hygiene practice. Journal of clinical psychology, 7(1), 1-94.

Walsh, J. F. (2010). Psychoeducation in mental health. Lyceum Books.

Wong, D. L., Hockenberry, M. J., \& Wilson, D. A. (2007). Wong's nursing care of infants and children. St Louis, Mo: Mosby. This Page Intentionally Left Blank.

Woolfolk, R. L., \& Lazarus, A. A. (1979). Between laboratory and clinic: Paving the twoway street. Cognitive Therapy and Research, 3(3), 239-244.

Yusuf, S. (2009). Mental hygiene: terapi psiko-spiritual untuk hidup sehat berkualitas. Penerbit Maestro: Bandung. 